seemed to be superior to electrocardiography, clinical examination, and the newer creatine kinase MB mass assays. ${ }^{2}$ These trials confirm that troponin $T$ is a powerful and independen predictor of an adverse outcome and that this predictive function extends well beyond admission to hospital. ${ }^{2}$ The prognostic importance for the cohort with a final diagnosis of myocardial infarction has been addressed elsewhere. ${ }^{3}$

Patients were retrospectively given their final diagnostic classification when all investigational data were available. All were initially admitted with a suspected acute coronary syndrome Patients classified as having unstable angina were required to have evidence of coronary artery disease-that is, either a subsequent cardiac event or results of investigations indicating such disease, as described in the paper. Patients classified as having non-ischaemic chest pain had negative results of exercise tests or normal coronary angiograms or thallium scans and underwent further investigations, including ventilation-perfusion lung scanning and gastroduodenoscopy, before being given their final diagnostic classification. None of this cohort had any cardiac event on follow up. We therefore believe that this hierarchical diagnostic categorisation protocol allows a clearer definition of unstable angina in our population than the heterogeneous definitions used by other study groups. With the development of a rapid assay and the next generation of assays for troponin $T$ (which are more sensitive and cardiospecific), ${ }^{4}$ this marker can now be measured more widely.

While we hold the view that measurement of troponin $T$ is a useful addition to current practice in stratifying the risk for patients admitted with acute coronary syndromes, we concur with Kennedy's view that it should not be used as the sole discriminant of risk.

PETER STUBBS Lecturer in cardiovascular medicine MARK NOBLE Weston professor of cardiovascular medicine Charing Cross and Westminster Medical School, London W6 8RP

PAUL COLIINSON Consultant chemical pathologist Mayday University Hospital NHS Trust, Croydon CR4 7YE

DAVID MOSELEY Senior medical laboratory scientific officer TREVOR GREENWOOD

West Middlesex University NHS Trust, Consultant cardiologist Isleworth TW7 6AF

1 Ohman EM, Armstrong P, Christenson R, Granger C, Katus $\mathrm{H}, \mathrm{Hamm} \mathrm{C}$, et al. Cardiac troponin T levels for risk stratification in acute myocardial ischemia. $N \mathrm{Engl} f \mathrm{Med}$ 1996;335:1333-41.

2 Lindahl B, Toss $H$, Venge $P$, Wallentin $L$ for the FRISC Study Group. Relation between troponin $T$ and the risk of subseGroup. Relis quent cardiac events in uns
Circulation 1996;93:1651-7.

3 Stubbs P, Collinson P, Moseley D, Greenwood T, Noble M. The prognostic significance of admission troponin $T$ The prognostic significance of admission troponin $\mathrm{T}$ concentrations
$1996 ; 94: 1291-7$.

4 Collinson P, Thomas S, Siu L, Vasudeva P, Stubbs P, CanepaAnson R. Rapid troponin T measurement in whole blood for detection of myocardial damage. Ann Clin Biochem 1995;32:454-8.

\section{Health for all by the year 2000}

\section{WHO is spearheading global consultation to update policy on health for all}

EDITOR, $\rightarrow$ Staffan Bergström and Pascoal Mocumbi highlight several impediments to the attainment of health for all. ${ }^{1}$ In so doing they provide a too pessimistic view of past successes and future opportunities.

At the World Health Organisation/Unicef conference in Alma-Ata in 1978 the concept of health for all was accepted as a motivational vision for the world. ${ }^{2}$ The "revolutionary" ideas of the primary health care strategy included an emphasis on intersectoral action for health, reallocation of health resources from tertiary care to community based health promotion and disease control, participation by the community, and scientifically validated interventions. These are now mainstream concepts and are being increasingly applied in developed and developing countries.

In terms of increases in life expectancy, decreases in infant mortality and in the prevalence of many infectious diseases, and improved access to environmental health and basic maternal and childhood preventive and promotional services, there have been substantial global health gains since the conference in Alma-Ata. ${ }^{3}$ Nevertheless, along with these gains the WHO has documented numerous obstacles, such as increased inequality in health and wealth in many countries.

As the global health community prepares for the 21 st century the WHO is spearheading a global consultation aimed at renewing the concept of health for all. This broad based process aims to update the old policy and add components that address the present and future context of health development. The WHO believes that health for all remains a powerful vision for the 21 st century. Yet we are not naive; we realise that certain serious challenges threaten future progress, and in this respect we welcome the authors' identification of macroeconomic factors that influence health. These same factors have been repeatedly emphasised by the WHO's task force on health and development, ${ }^{4}$ of which Mocumbi is a member.

The WHO is realistic, however, about its direct role in alleviating poverty. We will continue to document the root causes of ill health and poverty. We will continue to advocate development policies that reduce inequalities in wealth, build long term human and institutional capacity, use intersectoral approaches, and encourage sustainable development. Beyond advocacy, the WHO supports actions within the health sector that directly reduce the burden of disease and thereby help to improve the scholastic performance of children, increase the productivity of workers, and alleviate human suffering. These direct inputs, when combined with basic education, can accelerate populations' escape from poverty.

F S ANTEZANA

World Health Organisation,

Assistant di

CH-1211 Geneva,

27 Switzerland

Bergström S, Mocumbi P. Health for all by the year 2000? $B M 7$ 1996;313:316. (10 August.)

2 World Health Organisation. Global strategy for health for all by the year 2000. Geneva: WHO, 1981 .

3 World Health Organisation. The world health report, 1995: bridg ing the gaps. Geneva: WHO, 1995.

4 World Health Organisation. Health in development: prospects for the 21st century. Report of the first meeting of the task force on health in development. Geneva: WHO, 1994.

\section{Much can still be done}

EDITOR,-Staffan Bergström and Pascoal Mocumbi provide a telling description of the health burdens now confronting developing populations. ${ }^{1}$ Jordan affords a glaring example of the "debt trap" depicted by the authors: "Pressured by the International Monetary Fund, the Jordanian government raised the price of bread from 12 [US] cents [7p] to 26 cents per $\mathrm{kg}$, and of more than 20 other basic food items." In Uganda the equivalent of $\$ 3(£ 1.86)$ a head is being spent annually on total health services, compared with $\$ 17$ ( $£ 10.56)$ required for the repayment of debt. ${ }^{3}$ In South Africa the situation is less acute. From figures given in parliament, for every 100 South African (SA) cents (26 US cents, $16 \mathrm{p}$ ) that the government spends, 18.7 SA cents is required for redemption of debt, while
21.2 SA cents is spent on education, 9.9 SA cents on health, and 9.6 SA cents on welfare.

Although the authors maintain that "health for all is a distant dream," some positive changes are occurring. ${ }^{4}$ Thus in all African countries infant mortality has fallen considerably. In South Africa infant mortality among Africans in big cities is $20-25 / 100000$. While this is triple that among the white population, it compares favourably with that among Afro-Americans (17/100 000) furthermore, rates in minority populations, such as New Zealand Maoris and Australian Aboriginals, are of the same order.

Despite the fearful outlook for developing populations, improvements in health, wellbeing, and community spirit can still be made. The involvement of women must certainly be supported. In this respect, governments' increasing willingness to address women's rights and needs in policy and programmes is encouraging. The previous director general of the World Health Organisation, Dr Halfden Mahler, often emphasised women's important role in health promotion-their role in delivering babies, as volunteers in hospitals, in self help clinics, and in other community organisations and practices. Skilled nurses could be given greater responsibilities in rural hospitals; with training they could conceivably undertake emergency surgery. More mutual help in the community is also effective, as exemplified by the outstanding experience of Kerala, one of the poorest states in India." Whereas Kerala's infant mortality is about $30 / 100000$, that of India as a whole is $40-50 / 100000$. Additionally, greater use must be made not only of health workers based in the community but of traditional healers.

While health for all is a dream for African countries, there is much that is positive and much that can still be done, if not to better then at least to restrain the inevitably worsening economic and health scenarios.

ALEXANDER R P WALKER

Human Biochemistry Research Unit,

Department of Tropical Diseases,

South African Institute for Medical Research,

Johannesburg,

Johannesburg,

LESLEY T BOURNE Researcher

Urbanisation and Health,

Medical Research Council,

Cape Town,

South Africa

BARBARA J KLUGMAN

Women's Health Project,

Department of Community Health,

University of the Witwatersrand,

Johannesburg,

South Africa

1 Bergström S, Mocumbi P. Health for all by the year 2000 ? $B M$ f 1996;313:316. (10 August.)

2 Talk of the streets. Give us this day our daily bread. Time 1996;148:12.

3 Benatar SR. The World Bank, listening and learning. Lancet 1996;347:1047.

4 Walker ARP, Walker BF, Glatthaar II. Impoverished Africa: any hope for the future? $\mathcal{F} R$ Soc Med 1994;87:157-60.

5 Kutty VR. Women's education and its influence on attitude to aspects of child-care in a village community in Kerala. Soc Sci Med 1989;29:1299-303.

\section{Code of practice on managing tuberculosis is satisfactory}

EDitoR,-Julia E Clark and Andrew J Cant report three cases of childhood tuberculosis and discuss their management in relation to the 1994 code of practice of the joint tuberculosis committee of the British Thoracic Society. ${ }^{12}$ They conclude that all children in contact with tuberculosis should have a chest $x$ ray examination irrespective of the result of the initial tuberculin test. We do not believe that this recommendation is justified for the following 
reasons. Two of the authors' cases (cases 1 and 3) were not managed in accordance with the guidelines, and in case 2 negative results of tuberculin tests six weeks apart meant that no chest $x$ ray film was obtained, and primary tuberculosis was diagnosed shortly afterwards.

The 1994 code of practice superseded that of 1990 , and the recommendations with regard to contact tracing were based on five contact studies (referenced in the code ${ }^{2}$ ) of a total of 22971 contacts, including many children. These studies showed that contacts found to have clinical tuberculosis are largely unvaccinated close contacts of people with sputum smear positive disease and that detection usually occurs at the initial visit. Because of possible delays in tuberculin conversion, in children it is advised that the tuberculin test is repeated after six weeks if the initial test gives a negative result and that children under the age of 2 years are given prophylaxis with isoniazid pending the result of this repeat test.

Chest radiography regardless of the result of the first tuberculin test is also not justified for two reasons. Firstly, there is little evidence that non-pulmonary tuberculosis is infectious to others, including children. Secondly, unnecessary radiation is to be avoided in children. Many children could well have radiography for which there is insufficient justification.

The 1994 code of practice will be audited and its effectiveness monitored. However, as the recommendations were based on large studies from five separate centres, none of which found the problems reported by Clark and Cant, more would be required than evidence from a single case before any change to strongly evidence based recommendations could be justified. In view of the unfortunate delay in reporting the history of contact with tuberculosis in case 2 it might be sensible to advise parents of children in whom tuberculin tests persistently give negative results of the small possibility of subsequent tuberculosis and of the need to report relevant symptoms and the history of exposure.

For the Joint Tuberculosis Committee of the British Thoracic

PETER ORMEROD

Blackburn Royal Infirmary,

Consultant chest physician

Blackburn BBE 3LR

JOHN WATSON

Consultant epidemiologist

PHLS Communicable Disease Surveillance Centre,

London NW5 5EQ

CRAIG SKINNER Consultant chest physician

Birmingham Heartlands Hospital,

Birmingham B9 5SS

1 Clark JE, Cant AJ. Pitfalls in contact tracing and early diagnosis of childhood tuberculosis. BMF 1996;313:221-2. (27 July.)

2 Joint Tuberculosis Committee of the British Thoracic Society. Control and prevention of tuberculosis in the United Kingdom: code of practice 1994. Thorax 1994;49:1193-200.

\section{Sudden infant death syndrome}

\section{More attention should have been paid to socioeconomic factors}

EDITOR,-Chris Mihill and colleagues were right to complain that the breaking of the embargo on the report on the confidential inquiry into stillbirths and deaths in infancy ${ }^{2}$ and the accompanying papers in the $B M \mathcal{F}^{4}$ meant that there was inadequate time for the full data in the report to be studied. Given more time, journalists might have noticed major differences between the socioeconomic and other circumstances of babies whose death was attributed to the sudden infant death syndrome and control babies. These were not mentioned in the Department of Health's press release and were
Table 1-Comparison of babies whose deaths were classified as being due to the sudden infant were cyndrome and same health vitors' lists (source: ref 2). Figures are percentages of families except where stated otherwise

\begin{tabular}{|c|c|c|}
\hline & $\begin{array}{c}\text { Sudden } \\
\text { infant } \\
\text { death } \\
\text { syndrome }\end{array}$ & Controls \\
\hline \multicolumn{3}{|l|}{ Employment and Income } \\
\hline Neither parent employed & 44.6 & 15.4 \\
\hline $\begin{array}{l}\text { Neither parent had ever been } \\
\text { employed }\end{array}$ & 13.3 & 4.1 \\
\hline $\begin{array}{l}\text { Family income: } \\
<£ 100 \text { a week }\end{array}$ & 41.0 & 20.4 \\
\hline $\begin{array}{l}<£ 200 \text { a week } \\
\text { Receiving income support }\end{array}$ & $\begin{array}{l}72.8 \\
66.6\end{array}$ & $\begin{array}{l}47.8 \\
28.2\end{array}$ \\
\hline $\begin{array}{l}\text { No of families in sample } \\
\text { Education } \\
\text { No educational qualifications: }\end{array}$ & 195 & 780 \\
\hline Mother & 40.5 & 19.0 \\
\hline Partner & 33.7 & 18.7 \\
\hline $\begin{array}{l}\text { Parent with highest } \\
\text { qualifications }\end{array}$ & 24.3 & 11.0 \\
\hline A level or above: & & \\
\hline Mother & 12.5 & 25.0 \\
\hline Partner & 16.2 & 30.9 \\
\hline $\begin{array}{l}\text { Parent with highest } \\
\text { qualifications }\end{array}$ & 19.7 & 37.7 \\
\hline No of families in sample: & & \\
\hline Mother & 193 & 775 \\
\hline Partner & 166 & 699 \\
\hline $\begin{array}{l}\text { Parent with highest } \\
\text { qualifications }\end{array}$ & 193 & 776 \\
\hline Housing & & \\
\hline$\geqslant 2$ people per room & 10.8 & 0.8 \\
\hline No of families in sample & 194 & 778 \\
\hline$\geqslant 6$ people in household & 21.6 & 9.9 \\
\hline No of families in sample & 195 & 780 \\
\hline Damp or mould in baby's room & 13.5 & 7.2 \\
\hline $\begin{array}{l}\text { No of families in sample } \\
\text { Bables* }\end{array}$ & 193 & 778 \\
\hline $\begin{array}{l}\text { Born before } 37 \text { weeks' gestation } \\
\text { Birth weight }(g) \text { : }\end{array}$ & 18.0 & 4.3 \\
\hline$<1500$ & 3.6 & 0.6 \\
\hline$<2500$ & 21.1 & 4.2 \\
\hline No of babies in sample & 195 & 778 \\
\hline
\end{tabular}

"Figures are percentages of babies.

mentioned only in passing in the report's executive summary and the papers.

The two papers restricted their focus to the sleeping environment ${ }^{3}$ and to smoking and the use of alcohol and illegal drugs. ${ }^{4}$ The first paper mentioned that the "effect modifiers" included several markers of socioeconomic status that differed between the cases and controls and that the differences may underestimate the differences in the population as a whole because of the way in which the controls were selected. Data to show the extent of these major differences were published only in the report of the confidential inquiry. ${ }^{2}$ Table 1 shows that many of the households in which sudden infant deaths occurred were in the more deprived sectors of society.

The authors' multivariate analyses showed differences in environmental and behavioural factors after adjustment for these social factors but did not explore possible associations further. Thus they did not question whether the strengths of the associations between the sudden infant death syndrome and risk factors varied between social groups. A recent study in Victoria, Australia, compared groups, defined by ethnicity and place of birth, that had differen rates of the syndrome. It did not find the expected associations with rates of prone sleeping, bed sharing, breast feeding, and smoking by family members other than the mother or a straightforward association with smoking by mothers. ${ }^{5}$

Account needs to be taken of social and economic factors when possible strategies for prevention are explored. To dismiss the factors by using the statistical term "effect modifier" is likely to understate their impact on people's lives, the problems that people may encounter in caring for a new baby, and the barriers to responding to advice about the hazards of smoking, alcohol, and illegal drugs.

The authors state that it is a good idea to avoid smoking. Should they have added that it is also a good idea to avoid being born into a poor household? Whatever the answers, the questions should have been publicly aired. The breaking of the press embargo ensured that this did not happen.

ALISON MACFARLANE Medical statistician

National Perinatal Epidemiology Unit,

Radcliffe Infirmary,

Oxford $\mathrm{OX} 26 \mathrm{HE}$

1 Mihill C, Pope N, Hunt L, Cooper G, Fletcher D. BMJ's embargo should not be broken. BMF 1996;313:305. (3 August.)

2 National Advisory Body for CESDI. Annual report 1994. London: Department of Health, 1996.

3 Fleming PJ, Blair PS, Bacon C, Bensley D, Smith I, Taylor E, et al. Environment of infants during sleep and risk of the sudden infant death syndrome: results of the 1993-5 case-control study for confidential inquiry into stillbirths and deaths in infancy. $B M F$ 1996;313:191-5. (27 July.)

4 Blair PS, Fleming PJ, Bensley D, Smith I, Bacon C, Taylor E, et al. Smoking and the sudden infant death syndrome: results from the 1993-5 suden infant death syndrome inquiry into stillbirths and deaths in infancy. $B M \mathscr{J}$ inquiry into stilbirths

5 Potter A, Lumley J, Watson L. The 'new' risk factors for SIDS: is there an association with the ethnic and place of birth differences in incidence in Victoria, Australia? Early Hum Dev 1996;45:119-31.

\section{Smoking is part of a causal chain}

EDITOR,-Peter S Blair and colleagues suggest that over $60 \%$ of cases of the sudden infant death syndrome may be attributable to the effects of parental smoking. ${ }^{1}$ This depends on the assumption that the association described is causal.

While smoking is undoubtedly harmful to babies, the magnitude of the risk is less clear. The close correlation between adverse socioeconomic circumstances and smoking and between risk of the sudden infant death syndrome and deprivation requires that the analysis should take careful account of potential confounding. The importance of the association between the syndrome and deprivation is suggested by the univariate odds ratios associated with social factors quoted in the full report of this study ${ }^{2}$-for example, receipt of family income supplement, 6.27; income of $<£ 200 /$ week, 3.57; living in rented accommodation, 3.81 ; and $<0.5$ rooms per person, 31.3 . To avoid residual confounding, the measure of socioeconomic status used for adjustment in multivariate analyses needs to split the population into relatively homogeneous bands. To adjust for low socioeconomic status the authors seem to use receipt of family income supplement, dividing the population into two heterogeneous groups. ${ }^{3}$ Blackburn and Graham have shown, however, that even among women in receipt of income support (a more homogeneous group) the risk of smoking during pregnancy is strongly related to the degree of deprivation. ${ }^{4}$ This raises the potential for appreciable residual confounding.

While acknowledging that social variables remain significant after adjustment, the authors have chosen to concentrate on behavioural variables on the grounds that social variables are "not amenable to change." Between 1979 and 1987 the proportion of British children in families with less than half the mean household income increased from $12 \%$ to $26 \% .^{5}$ This suggests that social factors are amenable to change over quite short periods.

Smoking is harmful, but to lay responsibility for deaths due to the sudden infant death 